\title{
Intelligent Dust Monitoring Application in Patient Room
}

\author{
https://doi.org/10.3991/ijoe.v17i10.24831 \\ Siwipa Pruitikanee, Jinda Kongcharoen $\left.{ }^{(}\right)$, Supattra Puttinaovarat, \\ Aisariya Thongkaew, Nuttawut Kongdee \\ Prince of Songkla University, Surat Thani Campus, Surat Thani, Thailand \\ jinda.suvepsu.ac.th
}

\begin{abstract}
Due to an ongoing epidemic, the number of hospitalized bedridden patients has increased. It is imperative to closely monitor the hospital room and maintain and clean it regularly to avoid harm to the patients. The accommodations may not be within the standards for a bed-bound patient's room. The patient has a risk of contracting a respiratory disease, or having an asthmatic attack, if exposed to high levels of PM1, PM2.5, or PM10 dust that cannot be seen with bare eyes, so the risk factor is not easy to notice. The goal of this study was to develop a dust monitoring system for hospital bedrooms using IoT, so that the caregivers can monitor air quality in the room. By applying the Internet of Things (IoTs) technology to communicate between sensors and mobile phones, the in ternet serves as the medium for communication. The demonstration system in the room was equipped with 5 sensor cluster, each measuring: temperature, humidity and dust sensors for PM1, PM2.5, and PM10. Decision trees were trained to predict the outcome of cases after collecting data. The final decision tree model reached an overall classification accuracy of $92.8 \%$. The system could alert for housekeeping or turn on or off an automatic dust remover based on the amount of dust in the room. It also supports cleaning and dust removal to ensure that the bed patient's room is appropriate and reduces the risk of respiratory diseases caused by dust.
\end{abstract}

Keywords-IoT, Decision Tree, PM2.5, Humidity, Temperature, Patient, Correlation

\section{Introduction}

In Thailand, there is an increasing trend in ambient airborne particulate matter (PM) for example in the below 2.5 microns size range. PM 2.5 in the northern parts of Thailand was found to exceed the recommended upper limit in standards of the WHO, in 2019. There are a variety of human health problems from exposure to PM 2.5 dust (e.g. nonfatal heart attacks, aggravated asthma, allergies, eye irritation etc.). The main sources of dust are human activities, such as waste incineration, fuel combustion by various industrial vehicles, and dust from reactions of pollutant gases and industrial activities; and there is also natural dust from seawater evaporation or forest fires [1 4], Many factors, including temperature, PM 1, PM 2.5, and PM 10 levels, contribute to the prevalence of respiratory symptoms. 
According to statistical data from the Department of Health in 2019, an estimated 232,876 people were considered confined patients (homebound elderly or bedridden patients), and the annual numbers are on the increase in Thailand [5]. With the rapid increase in bedridden patients in developing countries, the characteristics of the lodging provided affect the patient's life. The bedridden patients cannot exercise, move about, or find a more pleasant environment. The bedridden patients need a safe environment in their room, and automation can contribute in such assisted living.

The transformation of economic structure in the government program known as Thailand 4.0 adopts innovation and technology for developing the country. Current smartphone technologies are widely used to support self-care. Smartphones provide devices and cameras that could be applied to develop applications that help patients [610]. Moreover, Internet of Things (IoTs) technology to communicate between sensors and mobile phones uses the internet as the medium of communication. Using IoT supports automation that can be precise, stable and affordable [11 - 13]. The IoT concept was used in this current study. The previous study [14] developed the main controller to turn on/off air conditioners and lights using IoT through IOS and Android. The contribution of this study is to further manage and analyze the initial environment data for dust monitoring solutions using IoT. The dust monitoring was based on real-time data from measurement sensors. The objective of this study was to develop a dust monitoring application for a bedridden patient's room with IoT. It allows the caregivers to receive real-time monitoring data and notifications regarding dust levels in the room. The advantages of this demonstrated automation for assisted living include simplicity and easy access.

This paper is organized as follows. Section II presents the system architecture with implementation of the sensors for PM, humidity, and temperature levels. Section III shows the results of data analysis and our discussion. Finally, Section IV wraps up with the conclusion and suggestions for further research.

\section{Methods and Materials}

\subsection{Design and overview of the system}

This work aimed to design, implement, and demonstrate a system with sensors in the room, and associated data management by using a smartphone connecting to a web server. The three components are hardware, mobile application, and intelligent monitoring, as shown in Fig. 1 and Fig 2.

The system consisted of measuring modules and dust remover subsystem, the user's mobile for reporting and database modules. They communicated with each other via the Internet as shown in Fig. 1 


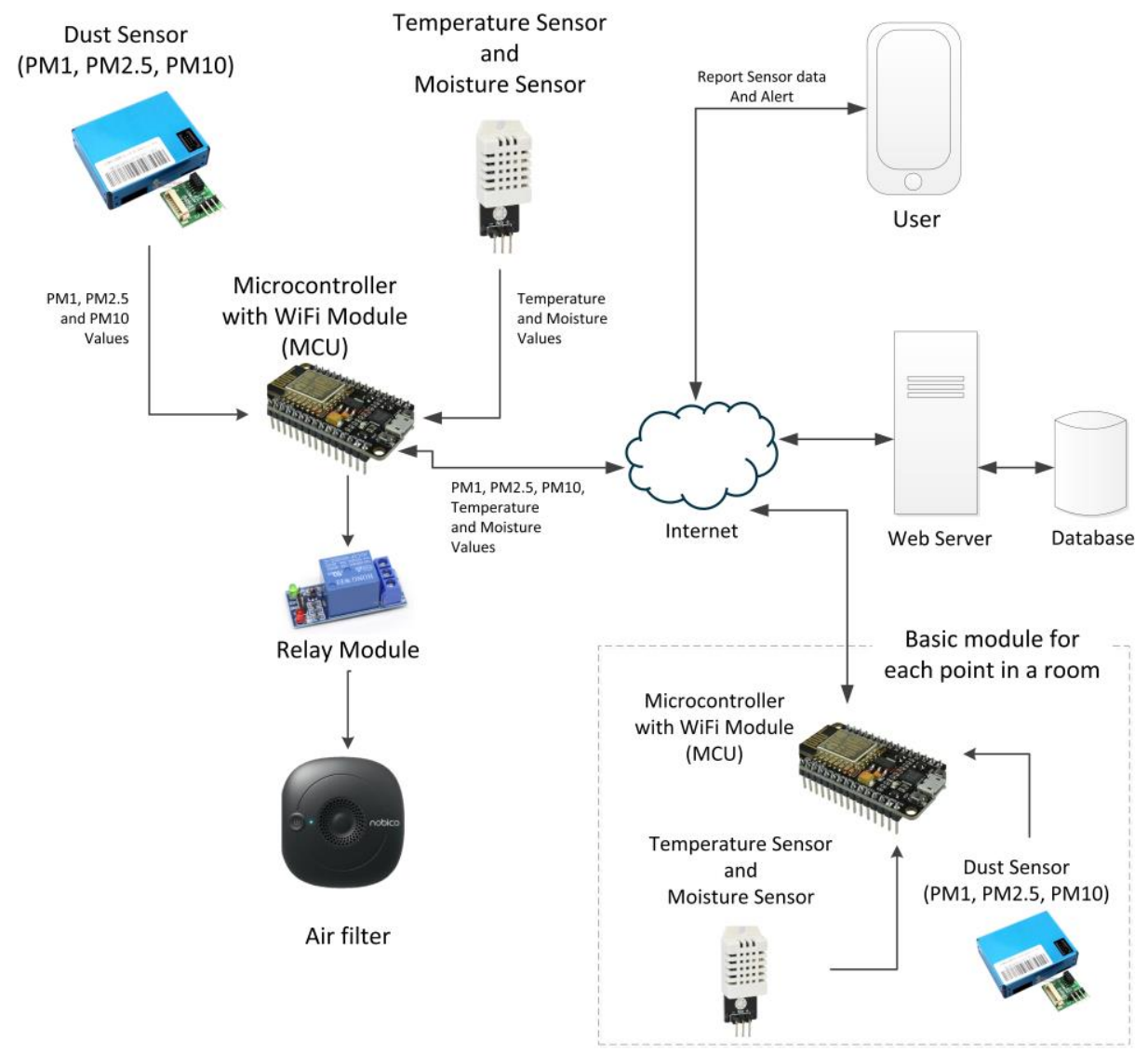

Fig. 1. The system overview

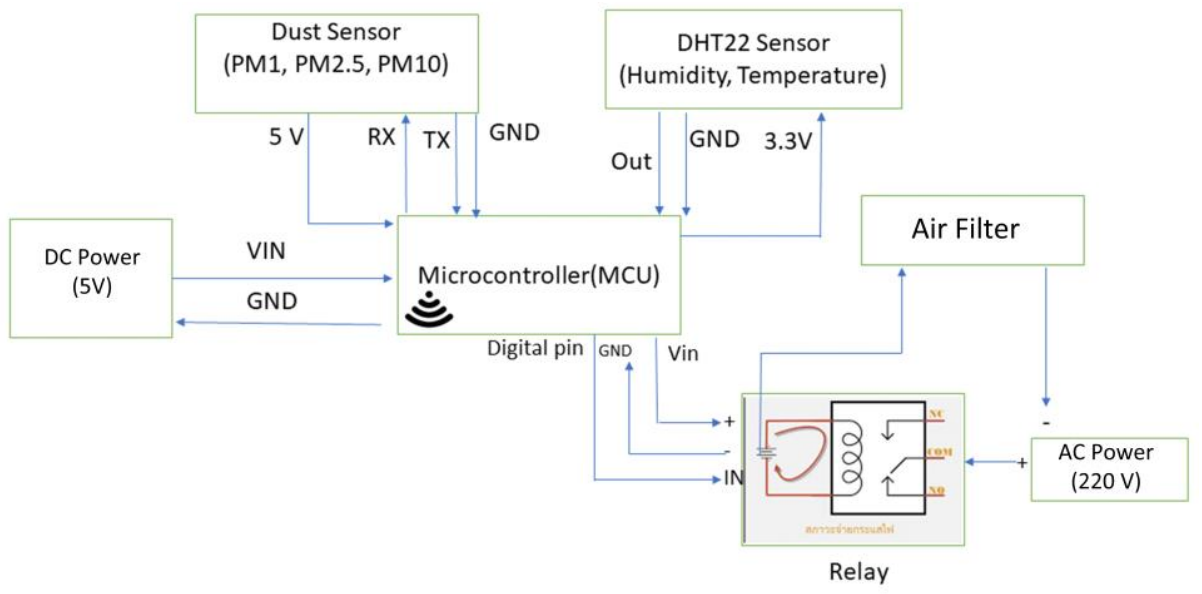

Fig. 2. Sensor cluster with dust remover 
Each measuring module contained 2 core parts: sensors and a microcontroller board. The sensor part consisted of a temperature sensor, a humidity sensor and a dust sensor (PM1, PM2.5, PM10). The microcontroller board was installed with the Wi-Fi module (MCU) to communicate with the database server by sending the sensor data from all sensors to record on the database server at the same time.

The dust remover subsystem contained the relay device and an air filter or dust remover as shown in Fig. 2 and control the relay device by releasing the electric power to turn on or off a dust remover following the decision rule based on the observed dust quality level.

The application on the caregiver's mobile phone aimed to report the dust quality and alert the risk message on each sensor cluster point. Therefore, it was designed into 5 main functions: connection configuration, sensor data retrieval, sensor data display, dust risk assessment calculation, and the alert of the risk points and the messages as shown in Fig. 3. The connection configuration was the first step to activate the system, to set the option values of the Wi-Fi network connection then the application automatically retrieved sensor data. Next step, the retrieved data was used to display and calculated the dust risk level. If there was poor dust quality, the application would be shown the sign on a risky sensor cluster point and sent the alert message to the caregiver immediately.

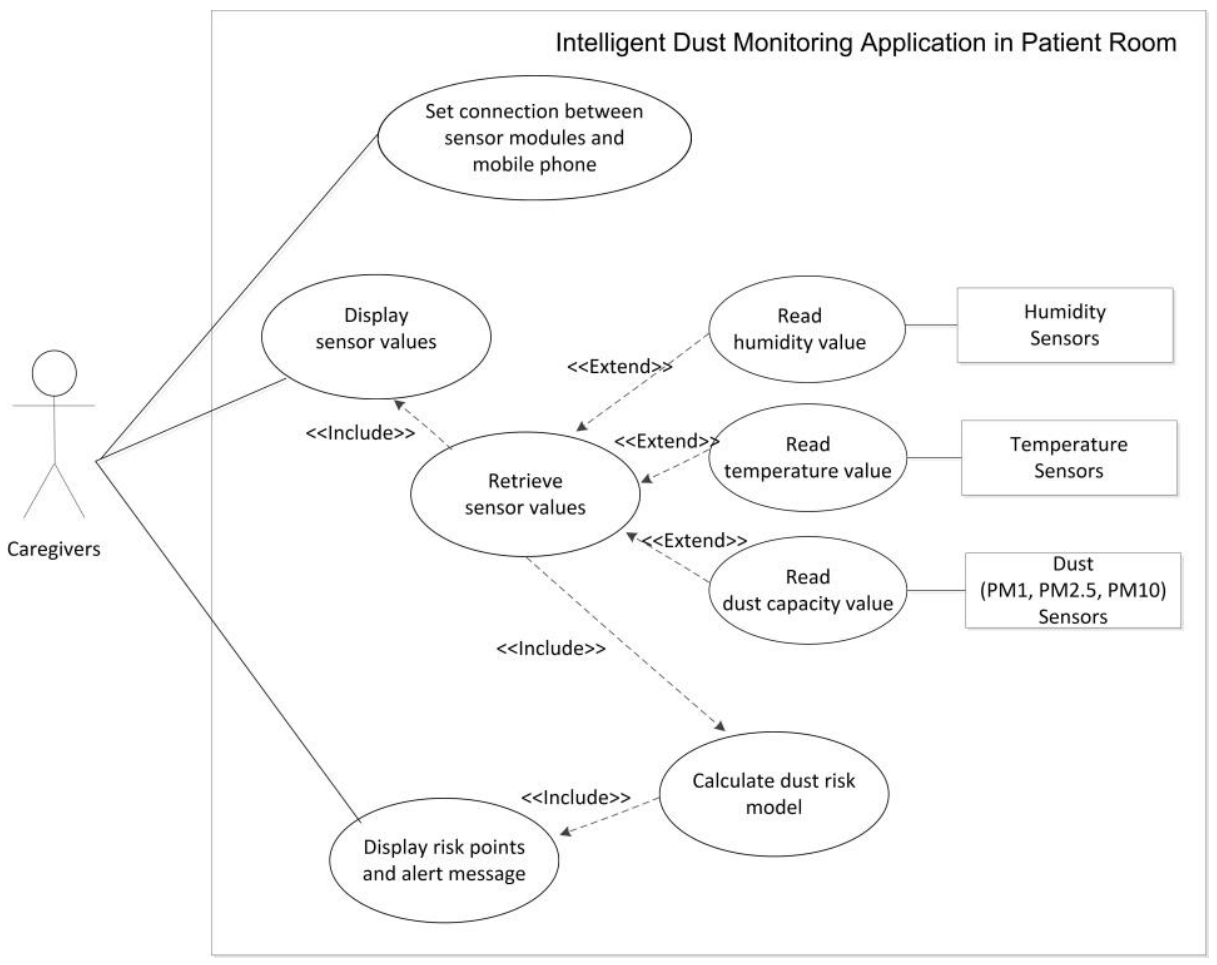

Fig. 3. Use case diagram of the proposed system 


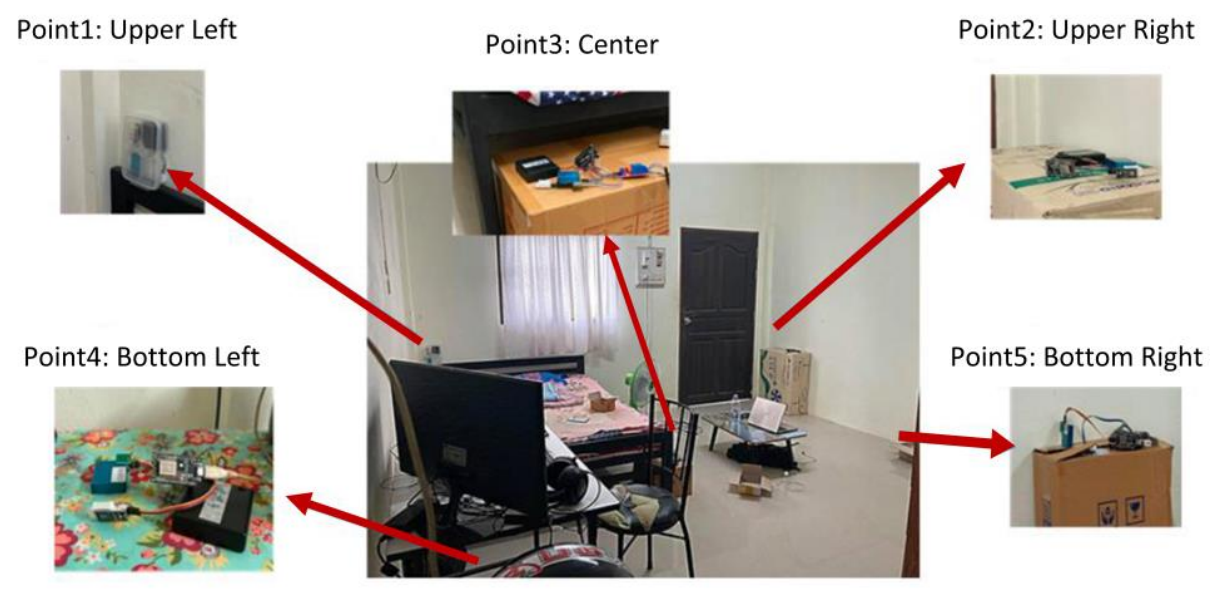

Fig. 4. Layout of experiment

The measuring devices were shown in Fig. 4. Sensor clusters were installed at 5 positions in the room (central, top left, bottom left, top right, bottom right). The dust remover was placed at the center point of the room. If the dust quality was harmful, the dust remover will automatically be turned on, running and turned off once the dust level was harmless.

\section{Results and Discussion}

The system consisted of two parts, namely the set of measuring devices, and intelligent monitoring. The proposed design was implemented successfully, and it was able to sense and send air quality data to the server. The user display showing results from devices is shown in Fig. 5. The PM, humidity and temperature levels at each position in the room were displayed in real time. The air quality is good or is bad (a), and the details of measured data at each position (b). 


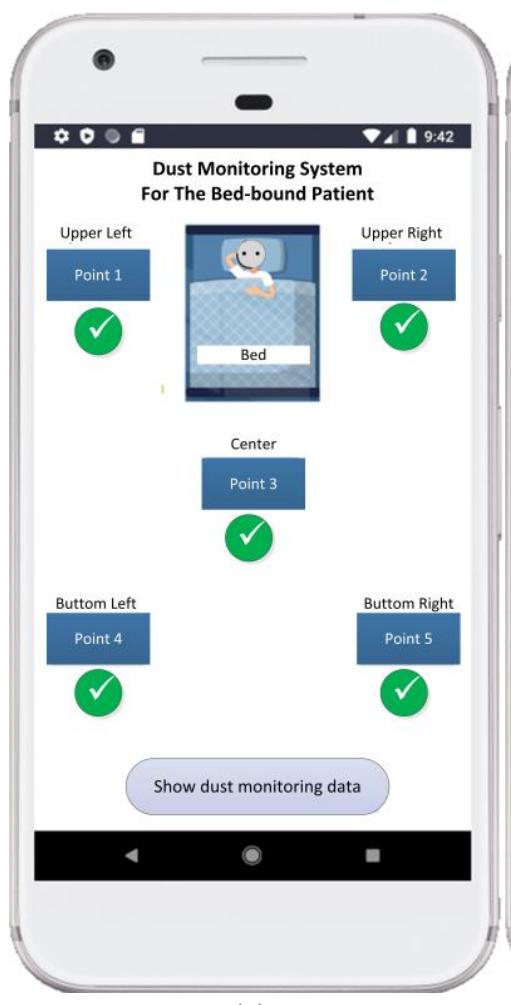

(a)

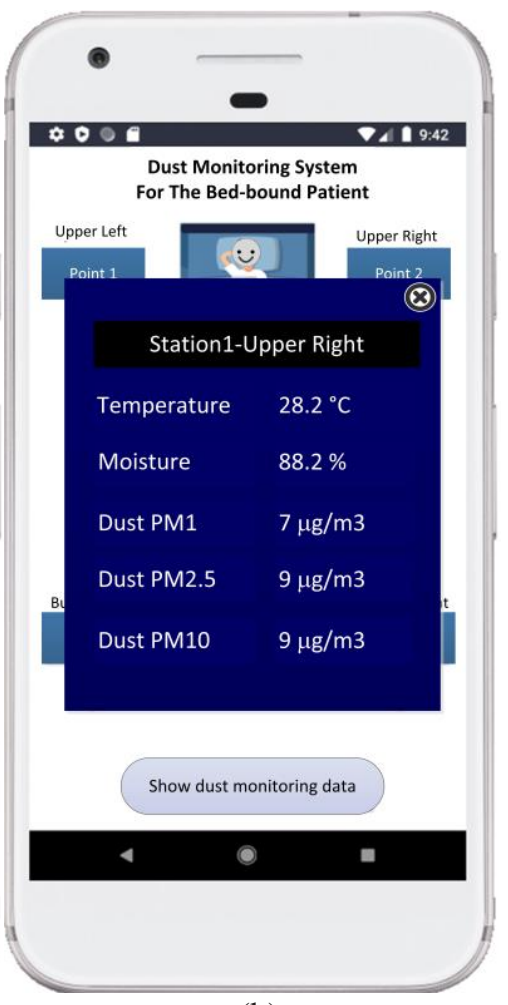

(b)

Fig. 5. An example of smartphone application displaying air quality in the room

\section{Intelligent monitoring}

From temperature, humidity and dust measurements in the room, the study collected time series data with 8 fields of various inputs. Fields 1-3 present the node_id, station_id and position, respectively. Fields $4-5$ display the temperature and humidity. Fields $6-8$ show the levels of PM 1.0, PM 2.5 and PM10 in air, respectively (Fig. 6).

The collected data from every sensor inside a 4x4 meter room over 51 days had 73,000 records. The associations among environmental characteristics with concentrations of PM were assessed from Pearson's correlation coefficients (Table 1). 


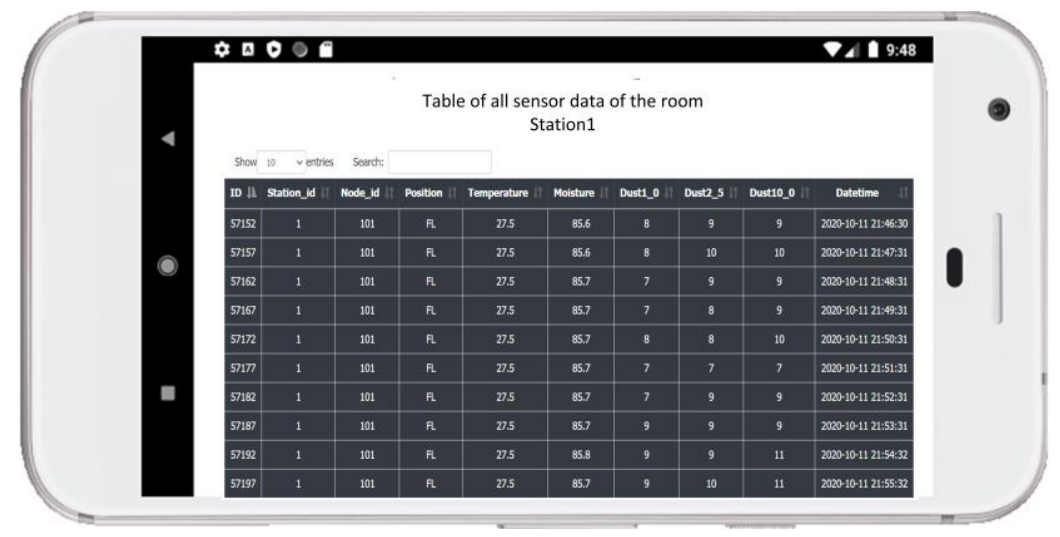

Fig. 6. The type of data collected in this study

Table 1. Pearson's correlations of factors

\begin{tabular}{|l|c|c|c|c|c|}
\hline Factors & PM1 & PM2.5 & PM10 & Temp & Humidity \\
\hline PM1 & 1.0000 & & & & \\
\hline PM2.5 & $0.9868^{* *}$ & 1.0000 & & & \\
\hline PM10 & $0.9833^{* *}$ & $0.9983^{* *}$ & 1.0000 & & \\
\hline Temp & -0.0643 & -0.0950 & -0.0989 & 1.0000 & \\
\hline Humidity & $0.1025^{* *}$ & $0.1299^{* *}$ & $0.1318^{* *}$ & $-0.8909^{* *}$ & 1.0000 \\
\hline
\end{tabular}

${ }^{* *} p<0.01$

The results indicated that humidity was significantly related with the concentrations of PM1, PM 2.5, PM10, with r $=0.1025,0.1299$, and 0.1318 respectively whereas temperature was related with concentrations of PM1, PM 2.5, PM10, with $r=-0.0643$, -0.0950 , and -0.0989 respectively. The three PM size classes were found to be positively correlated with the humidity, but negatively correlated with the temperature. Previous studies have indicated a significant positive correlation between the concentrations of PM10 and PM2.5 and humidity $[15,16]$. Our study agrees with these previous studies, indicating that humidity is the key factor influencing the concentrations of PM1, PM 2.5, PM10 in the room.

Using air quality data, the condition of the dust could be predicted given the concentration of various factors. The system can be utilized to design a monitoring system when the dust gets severe, and measures could be taken to mitigate this. The risk assessment criteria set by the Silica Permissible Exposure (PEL) standard limits the PM1 and PM2.5 to not exceed $50 \mu \mathrm{g} / \mathrm{m}^{3}$, and the limit is $120 \mu \mathrm{g} / \mathrm{m}^{3}$ for PM10. Machine learning algorithms were trained to predict the outcome after collecting data. The final decision tree model reached an overall classification accuracy of $92.8 \%$. The testing result of the dust in the room was used to implement the system alert for housekeeping and to automatically turn on or off a dust remover.

In this study, the PM 2.5 and humidity factors were used to control switching onand-off the dust remover automatically. The rules used were (Fig. 7)

if PM2.5 > 50.500 then switch on dust remover 
else if PM $2.5<=50.500$ and Humidity $>59.950$ then switch off dust remover else if PM $2.5<=50.500$ and Humidity $<=59.950$ then switch on dust remover

The finding from this study agreed with a previous study by Purwanto et al. [17] in terms of the humidity control system significantly influencing the design of room.

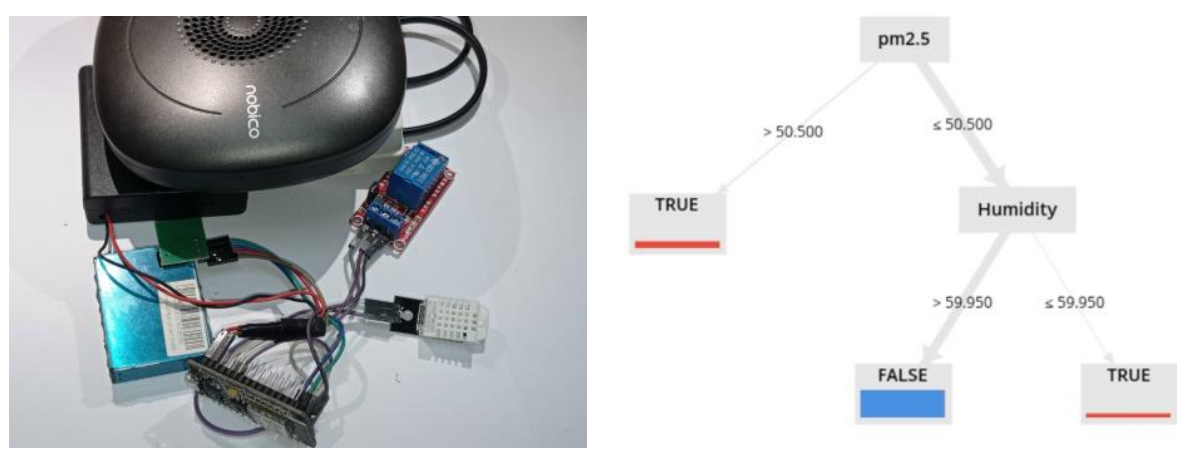

Fig. 7. The control unit switching dust remover on or off followed the rules in a decision tree

For risk assessment, the system will send a notification message to the caregivers via the LINE smartphone app. A notification message for cleaning the room is shown in Fig. 8.

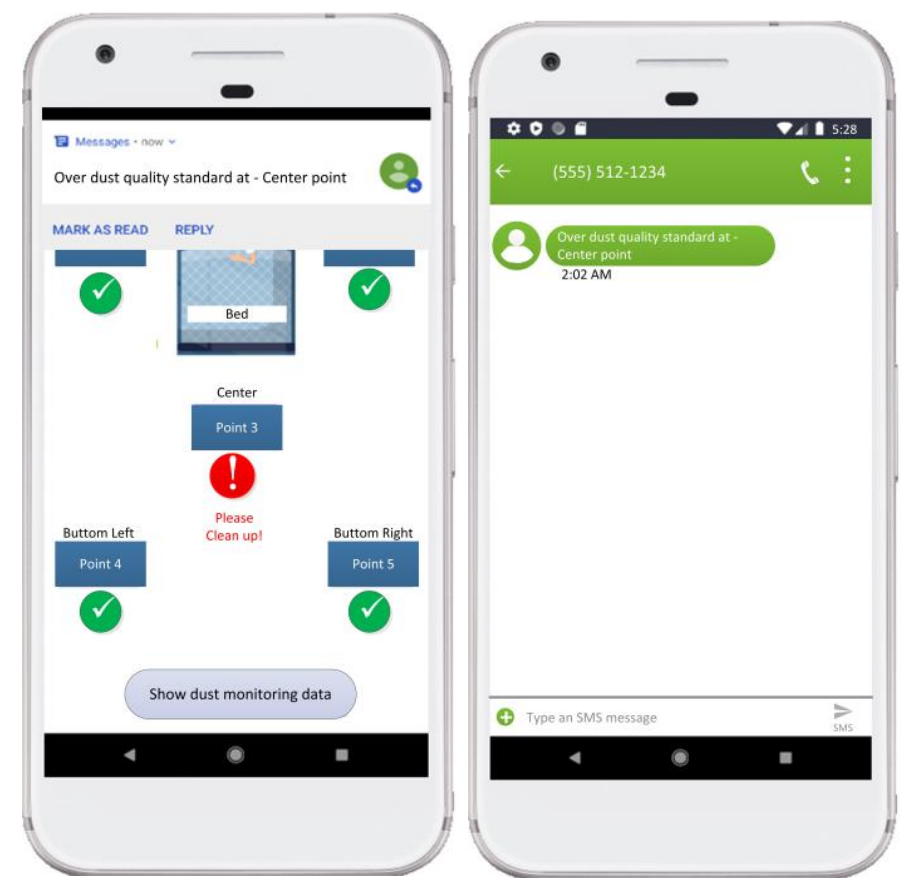

Fig. 8. Alerts for cleaning 
The healthcare system is needed at home. Previous studies [18 - 19] have developed the existing systems through various sensors to report the quality of dust. This study contributes to an intelligent monitoring system that alerts for housekeeping or turning on/off an automatic dust remover when a bad assessment is observed. The application offers cleaning and warning to detect the risks caused by dust. This application can be accessed by the smartphone. It allows the caregivers to monitor the dust level in realtime to improve the safety of patients at home.

\section{Conclusion}

Nowadays, the use of smartphones is ubiquitous. In this study, an intelligent dust monitoring application was implemented for a smartphone and demonstrated. The proposed application involves the integration of two main processes, which are the measuring devices, and the intelligent monitoring. The system was designed based on data from environmental sensors measuring PM1, PM2.5, PM10, humidity and temperature and these sensors sent data to servers for processing and storage. A decision tree was trained to predict the risk of excessive dust levels in the room. The mobile application displayed the call made by the decision tree, whether good or bad. Then, when a "bad" assessment was called, the system sent a notification to remind about cleaning the room, via LINE messaging app. The application allows the system to switch a dust remover on or off automatically. This system can be utilized to reduce the dust levels or improve the air quality inside a room using current technologies. Future studies should develop the monitoring system platform in health conditions. This will be beneficial for public health in the future.

\section{$5 \quad$ Acknowledgment}

The authors of this article would like to thank Prince of Songkla University, Surat Thani Campus, for funding support. The authors also thank Associate Professor Dr. Seppo Karrila for his valuable suggestions to improve the manuscript.

\section{$6 \quad$ References}

[1] Dockery, D.W., (2009). Health effects of particulate air pollution. Ann. Epidemiol, 19(4): 257-263. doi: 10.1016/j.annepidem.2009.01.018.

[2] Nadadur S.S., Hollingsworth J.W. (2015). Air pollution and health effects. London: Springer. http://dx.doi.org/10.1007/978-1-4471-6669-6.

[3] Prapamontol, T., Kerdnoi, T., Hongsibsong, S., et al. (2015). Surveillance of climate change, smog pollution and health impact in high hotspot areas in Chiang Mai Province. Center of Excellence for the Effects of Climate Changes on Environments and Natural Resources of Thailand.

[4] Phornwisetsirikun, W., Prapamontol, T., Rangkakulnuwat, S. et al. (2014). Effect of ambient PM10 on respiratory health of school children in Chiang Mai city, northern Thailand. the 
International Conference on Environmental and Occupational Health (ICEOH), 7-9 April 2014, Putra Jaya, Malaysia. https://doi.org/10.12982/cmujns.2014.0040

[5] Department of Health (2019). Bureau of Elderly Health Annual Report 2019. Thailand.

[6] Priana, A. J., Tolle, H., Aknuranda, I., Aristijono, E. (2018). User experience design of stroke patient communications using Mobile Finger (MOFI) Communication Board with User Center Design Approach. International Journal of Interactive Mobile Technologies (iJIM). 12(2):162-176. https://doi.org/10.3991/ijim.v12i2.7937

[7] Kongcharoen, J., Pruitikanee, S., Puttinaovarat, S. Tubtiang, Y. and Chankeaw, P. (2019). Gamification Smartphone Application for Leg Physical Therapy. International Journal of Online and Biomedical Engineering, 15(8): 31-41. https://doi.org/10.3991/ijoe.v15i08 .10488

[8] Saeliw, A., Hualkasin, W., Khaimook, K. and Puttinaovarat, S. (2019). Smart Car Parking Mobile Application based on RFID and IoT. International Journal of Interactive Mobile Technologies (iJIM), 13(5): 4-14. https://doi.org/10.3991/ijim.v13i05.10096

[9] Bobtong, J., Manraden, I., Kongcharoen, J., Pruitikanee, S., and Puttinaovarat, S. (2018). Getting lost monitoring system for the elderly patients. Rajamangala University of Technology Isan, 11(3): 89-100. https://ph01.tci-thaijo.org/index.php/rmutijo/article/view/167577/ 120752

[10] Puttinaovarat, S., Pruitikanee, S., Kongcharoen, J. and Horkaew, P. (2021). Machine Learning based emergency patient classification system. International Journal of Online and Biomedical Engineering, 17(5): 133-146. https://doi.org/10.3991/ijoe.v17i05.22341

[11] Saqib, M., Almohamad, T.A., and Mehmood, R.M. (2020). A Low-Cost information monitoring system for smart farming applications. Sensors (Basel, Switzerland), 20(8): 2367. https://doi.org/10.3390/s20082367

[12] Wongprasadpetch, S., Manowan, P. Srisot, C. Boongoen, T. Yooyativong, T. and Chansareewittaya, S. (2020). Monitoring system platform for agricultural research and analysis. JIST, 10(1): 70-74. https://ph02.tci-thaijo.org/index.php/JIST/article/view/240840/163975

[13] Kumsawat, P. (2018). Environment reporting system in agriculture farm using Low-cost Android-based Wireless Sensor Network. School of Telecommunications Engineering, Suranaree. University. http://sutir.sut.ac.th:8080/jspui/handle/123456789/7428

[14] Kaewphaitoon, S. and Lekchareon, S. The smart classrooms system with Internet of Things (IOT) through Andriod and IOS. The 13th RSU National Graduate Research Conference. 2839-2852. https://rsujournals.rsu.ac.th/index.php/rgrc/article/view/1042/799

[15] Zhao, C.X., Wang, Y.Q., Wang, Y.J. (2014). Temporal and spatial distribution of PM2.5 and PM10 pollution status and the correlation of particulate matters and meteorological factors during winter and spring in Beijing. Huan Jing Ke Xue. 35(2): 418- 427. PMID: 24812928.

[16] Yan S., Cao H., Chen Y., et al. (2016). Spatial and temporal characteristics of air quality and air pollutants in 2013 in Beijing. Environmental Science \& Pollution Research. 23(14):13996-14007. https://doi.org/10.1007/s11356-016-6518-3

[17] Purwanto, F.H., Utami, E and Pramono, E. (2018). Design of server room temperature and humidity control system using fuzzy logic based on microcontroller. 2018 International Conference on Information and Communications Technology (ICOIACT): 390-395. https://doi.org/10.1109/icoiact.2018.8350770

[18] Jha, R.K. Air quality sensing and reporting system using IoT. Proceedings of the second international conference on inventive research in computing applications (ICIRCA-2020): 790-793. https://doi.org/10.1109/icirca48905.2020.9182796

[19] Choi, W., Hwang, D., Kim, J. and Lee, J. (2018). Fine dust monitoring system based on Internet of Things. 09: 1-4. https://doi.org/10.1109/ict-robot.2018.8549878 


\section{$7 \quad$ Authors}

Siwipa Pruitikanee is a lecturer in the Faculty of Science and Industrial Technology at Prince of Songkla University, Surat Thani Campus, Surat Thani, Thailand. Her interested research is information technology, especially health and hospital information system.

Jinda Kongcharoen is an Assistant Professor in the Faculty of Science and Industrial Technology at Prince of Songkla University, Surat Thani Campus, Surat Thani, Thailand. Her research interests are data modeling in health, information technology, predictive analytics, and classroom action research.

Supattra Puttinaovarat is currently an Assistant Professor with the Faculty of Science and Industrial Technology, Prince of Songkla University, Surat Thani Campus, Surat Thani, Thailand. Her research interests include flood modeling, geographic information systems, remote sensing, e-learning, and machine learning.

Aisariya Thongkaew is an undergraduate student of information technology in the Faculty of Science and Industrial Technology at Prince of Songkla University, Surat Thani Campus, Surat Thani, Thailand.

Nuttawut Kongdee is an undergraduate student of information technology in the Faculty of Science and Industrial Technology at Prince of Songkla University, Surat Thani Campus, Surat Thani, Thailand.

Article submitted 2021-06-16. Resubmitted 2021-07-23. Final acceptance 2021-07-25. Final version published as submitted by the authors. 